\begin{tabular}{ccc}
\hline \hline \hline & International Journal of Current Research in & \\
\hline & Biosciences and Plant Biology & \\
\hline $\begin{array}{c}\text { EXCELLENT } \\
\text { PUBLISHERS }\end{array}$ & ISSN: 2349-8080 (Online) • Volume 3 - Number 10 (October-2016) & Journal homepage: www.ijcrbp.com \\
\hline \hline
\end{tabular}

Mini Review

doi: http://dx.doi.org/10.20546/ijcrbp.2016.310.009

\title{
Green Nanotechnology - A Potential Tool for Insect Pest Management
}

\author{
Supriya Sadanand Gogate*
}

Department of Entomology, Assam Agriculture University, Jorhat -785013, India

*Corresponding author.

\begin{abstract}
A bstract
Each year, in agriculture, billions of dollars are spent worldwide in controlling insect pests. Lepidoptera is the second largest order of insects, with more than 150, 000 species worldwide, which causes yield loss of $30-35 \%$ from sowing up to storage condition. Until recently, broad spectrum chemical insecticides have been the primary control agent for agricultural pests, with about $40 \%$ targeted to the control of lepidopteran pests. Synthesis of silver nanoparticles from plant extracts is a pioneer technique. Preparation of plant extracts is very easy, cheap method and eco friendly in nature. Biological approaches using plant extracts for metal nanoparticles synthesis is a valuable alternative over chemical methods. The application of nanotechnology as supplement for the existing practices or strategies like trap cropping, biopesticides and pheromones are discussed in this review.
\end{abstract}

\section{Article Info}

Accepted: 10 September 2016

Available Online: 06 October 2016

\section{Keywords}

\section{Crop loss}

Green nanotechnology

Insect pest management

Nanoscience

\section{Introduction}

Pests are frequently mentioned as major constraints to improve food production, higher agricultural productivity. Insects, diseases and weeds destroy more than $40 \%$ of potential food production. Up to $15 \%$ crops are widely lost because of insect damage alone. The world health organization and UN Environmental programme estimate that each year 3 millions of workers in agriculture experience sever poisoning from pesticides and about 18000 of whom die. The pest management practices throughout world are fastly leaning towards environment friendly agriculture without disturbing balance of the ecosystem. So the evolution of modern organic agriculture depends on biological control agents to disrupt and control pest attack which impart serious adverse effect on agricultural economy.

Several practices including chemical, biological and biopesticides were used for insect pest management. The use of insecticides in agricultural fields leads to an ecological imbalance in nature and thus in some countries including India, several insecticides have been banned (Yadav, 2010). Several insecticides can alter the protease and chitinase activities of certain insect pests (Zhang and Xiao-Zhen, 2010). The use of neonicotinoid systemic insecticides in agricultural fields is harmful to natural enemies (Cloyd and Bethke, 2011). To overcome this situation, different forms of insecticides have been advocated.

Nanotechnology is foreseen to significantly influence science, economy and everyday life in the $21^{\text {st }}$ century and also to become one of the driving forces of the next industrial revolution. Nanoparticle synthesis has received considerable attention in recent years as a result of its optical, electronic, magnetic and chemical properties and their potential applications in subsequent technology development. The word 'Nano' developed from Greek word 'dwarf'. In the technical terms, the word 'nano' 
means $10^{-9}$ or one billionth of something. Nanotechnology is a promising field of research opens up wide array of opportunities and is expected to give major impulses to technical innovation in a variety of industrial sector.

\section{Preparation of nanoparticles}

Nanoparticles can be made by using various physiochemical method. Their synthesis using nanotoxic and environmentally benign biological method is attractive especially when they are intended for medicine. Several routed have been developed for biological or biogenic synthesis of nanoparticles from salt of corresponding metals. Microorganism, plant tissues and fruits, plant extracts and marine algae have been used for production of nanoparticles.

Plants provide a better platform for nanoparticles synthesis as they are free from toxic chemicals as well as provide natural capping agents. Moreover, use of plant extracts also reduces the cost of microorganisms isolation and culture media enhancing the cost competitive feasibility over nanoparticles synthesis by microorganisms. Plants and microbes are currently used for nanoparticle synthesis. The use of plants for the synthesis of nanoparticles is rapid, low cost, ecofriendly, and is a single-step method for biosynthesis process (Huang et al., 2007).

In nature living organism from bacteria to beetle rely on nanometer shaped protein machines that perform everything from whipping of flagella to flexing of muscles. Nanoparticles and other nanostructure material are often synthesized using chemical method. Target nanoparticles can be identifying with help of Scanning Tunnelling Microscope (STM) and Atomic Force Microscope (AFM). Silver nanoparticles play a significant role in field of biology and medicine due to their attractive physiochemical properties. The highly reactive metal oxide nanoparticles exhibit excellent bactericidal action against Gram positive and Gram negative bacteria (Stoimenov et al., 2002).

\section{Green synthesized nanoparticles -A journey from past to future}

Over the past decade Nanoscience and Nanotechnology is a sprouting interdisciplinary field of research material science, bionanoscience and technology to harness the benefit of life science, healthcare, industrial biotechnology. Nanotechnology is a recent discipline which has been also used in pest control. The ingenuity of nanotechnology is the potential to precisely form matter to atomic level specificity. Thus, the major benefit of employing nano-based pesticides is the opportunity to enhance properties such as efficacy and specificity. The potential uses and benefits of nanotechnology are enamours. These include agricultural productivity enhancement involving nanoporous zeolites for slow release and efficient dosage of water and fertilizer, nanocapsules for herbicidal delivery and vector, pest management and nanosensors for pest detections (Scrinis and Lyons 2007; Scott 2007). Nanoparticles help to produce new insecticides, pesticides and insect repellent (Owolade et al, 2008). Nanoencapsulation is process through which a chemical such as insecticides is slowly but efficiently released to particular host plant for insect pest control. Nanoencapsulation with proper absorption of chemical into plants unlike the case of larger particles.

Plant extract may act both as reducing agents and stabilizing agents in synthesis of nanoparticles (Kumar and Yadav, 2009). The source of plant extract is known to influence the characteristic of nanoparticles. This is because different extract contain different concentrations and combinations of organic reducing agents. Research on nanoparticles and insect control should be geared towards introduction of faster and ecofriendly pesticides in future (Bhattacharyya et al., 2007). It has been observed that nanoparticles loaded with garlic essential oil is efficacious against Tribolium castenum herbst (Yang et al., 2009). Alluminosilicate filled nanotubes have ability to stick to the surface hair of the insect pest and ultimately enters the body and influence certain physiological functions. The pediculocidal and larvicidal activity of synthesized silver nanoparticles using an aqueous leaf extract of Tinospora cordifolia showed maximum mortality against the head louse Pediculus humanus and fourth instar larvae of Anopheles subpictus and Culex quinquefasciatus (Jayaseelan et al., 2011).

\section{Conclusion}

Nanotechnology in agriculture plays a very important role in the slow release effects which includes pest control with increased shelf-life to various applications in the agricultural fields. This review indicates the importance of nanoparticles, with respect to the life cycle of the pest controlling it biologically. Nanotechnology is currently most promising technology for protection of host plant against insect pest. So Nanotechnology revolutionizes agriculture including insect pest management. 


\section{Conflict of interest statement}

Author declares that there is no conflict of interest.

\section{References}

Bhattacharyya, A., Debnath, N., 2008. Nano particles- A futuristic approach in insect population. In Proceedings on UGC Sponsored National Seminar on Recent Advances in Genetics and Molecular Biology, Biotechnology and Bioinformatics, Vidyasagar College, Kolkata.

Cloyd, R.A., Bethke, J.A., 2011. Impact of neonicotinoid insecticides on natural enemies in greenhouse and interiors cape environments. Pest Manage. Sci. 67(1), 3-9.

Huang, J., Li, Q., Sun, D., Lu, Y., Su, Y., Yang, X., Wang, H., Wang, Y., Shao, W., He, N., Hong, J. and Chen, C.,2007. Biosynthesis of silver and gold nanoparticles by novel sun dried Cinnamomum camphora leaf. Nanotech. 18, 103104.

Jayaseelan, C., Rahuman, A.A., Rajakumar, G., Vishnu, A.K., Santhosh kumar T., Marimuthu, S., Bagavan, A., Kamaraj, C., Zahir, A.A., Elango, G., 2011. Synthesis of pediculocidal and larvicidal silver nanoparticles by leaf extract from heartleaf moonseed plant, Tinospora cordifolia Miers. Parasitological Res. 109, 185-194.

Kumar, V., Yadav, S.K., 2011. Plant-mediated synthesis of silver and gold nanoparticles and their applications. J.
Chem. Technol. Biotechnol. 84, 151-157.

Owolade, O.F., Ogunleti, D.O., Adenekan, M.O., 2008. Titanium dioxide affects disease development and yield of edible cowpea. Agric. Food. Chem. 7(50), 2942-2947.

Scott, N.R., 2007. Nanotechnology Opportunities in Agriculture and Food Systems. Biological and Environmental Engineering, Cornell University NSF Nanoscale Science and Engineering Grantees Conference December 5, 2007, Arlington, VA.

Scrinis, G., Lyons, K., 2007. The emerging nano-corporate paradigm nanotechnology and the transformation of nature, food and agrifood systems. Int. J. Sociol. Agric. Food. 15(2), 22-44.

Stoimenov, P.K., Klinger, R.L., Marchin, G.L., Klabunde, K.J., 2002. Metal oxide nanoparticles as bactericidal agents. Langmuir. 18, 6679-6686.

Yadav, S.K., 2010. Pesticide applications-Threat to ecosystems. J. Hum. Ecol. 32(1), 37-45.

Yang, F.L., Li, X.G., Zhu, Lei, C.L., 2009. Structural characterization of nanoparticles loaded with garlic essential oil and their insecticidal activity against $T$. castaneum (Herbst) (Coleoptera: Tenebrionidae). J. Agric. Food Chem. 57(21), 10156-10162.

Zhang, S., Xiao-Zhen, Y.E., 2010. Impacts of chemical insecticides on extracellular protease and chitinase activities of Metarhizium anisopliae. J. Fujian College Forest. 4, 289-292.

\section{How to cite this article:}

Gogate, S. S., 2016. Green nanotechnology - A potential tool for insect pest management. Int. J. Curr. Res. Biosci. Plant Biol. 3(10), 76-78. doi: http://dx.doi.org/10.20546/ijcrbp.2016.310.009 